\title{
A Study of Nondermatophytic Dermatomycosis in Patients Attending a Tertiary Care Hospital in Vijayawada, Andhra Pradesh, India
}

\author{
V. Manjula* and K. Parameswari \\ Department of Microbiology, Siddhartha Medical College, Vijayawada, Andhra Pradesh, India \\ *Corresponding author
}

\section{A B S T R A C T}

Keywords

Superficial mycosis,

Dermatophytes,

Non dermatophytes,

Non dermatophyte

moulds,

Candida,

Malassezia.

\section{Article Info}

Accepted:

15 March 2016

Available Online:

10 April 2016
The present study was done to know the etiological role of Nondermatophytes in cases of dermatomycosis. The study was conducted on 150 suspected cases of superficial mycosis. Direct microscopy by $\mathrm{KOH}$ mount and culture was undertaken to isolate the fungal pathogens. 107 out of 150 cases(71.3\%) were positive by direct microscopy and 85 were culture positive among 150 cases. Males were affected more $(65.3 \%)$ than females(34.7\%). The commonest age group involved was 31-40 yrs. Tinea corporis was the most common clinical presentation (30\%-45 cases). Dermatophytes were most commonly isolated agents (57.6\%, 49 cases). Non dermatophytes were isolated from 36 cases $(42.4 \%)$ and include non dermatophyte moulds (21.3\%), Candida sps (17.6\%) and malassezia sps(3.5\%).The nondermatophyte moulds were the majority among the nondermatophytes among which Aspergillus spp were the most common. Others include Curvularia, Fusarium, Scopulariopsis etc. The candida species isolated were C.albicans, C.parapsilosis and C.krusei. Malassezia was isolated from three cases. It was concluded that along dermatophytes, non dermatophyte fungi are also emerging as important causes of superficial mycosis.

\section{Introduction}

Dermatomycosis is the superficial fungal infection of skin and its appendages caused by Nondermatophytes (Jagadish chander, 2009). The Nondermatophytes responsible are yeasts (Candida and Malassezia) and Nondermatophyte moulds (Aruna Agarwal et al., 2002). Their role in causing superficial infections have been well documented in many studies. Treatment of nondermatophyte infections is often difficult as topical and systemic antifungals are in effective (EI Batawi et al., 2006).
Dermatophytes and non dermatophytes are assuming greater significance both in developing and developed countries due to immuno compromised conditions like AIDS, cancer chemotherapy, neoplasm, immune suppressive drugs, excessive steroid use and metabolic disorders like Diabetes mellitus (Naidu J et al., 1993; Dogra S et al., 2002). So the present study was aimed to find out the role of Nondermatophytes as causative agents of dermatomycosis. 


\section{Materials and Methods}

The present study was a prospective study, carried out in the Department of Microbiology, Siddhartha medical college, Vijayawada, Andhra Pradesh during a one year period from August, 2013 to 2014. A total of 150 cases attending the dermatology O.P were screened. A detailed clinical history including age, sex, duration, site and extent of infection, type of lesion, antifungal therapy and occupation of patients was taken. Patients were examined and grouped in different clinical types depending on the site of involvement. Clinical specimens like skin scrapings, infected hair (by hair plucking) and clipped nails were collected in small paper envelopes after cleaning the area with $70 \%$ alcohol. All specimens were subjected to direct microscopy for fungal elements in $10 \%$ \& $20 \% \mathrm{KOH} \&$ culture in Sabouraud's Dextrose agar with chloramphenicol and antibiotics and with and without cycloheximide (Topley and Wilson, 2005).Tease mount, cellophane tape mount and slide cultures were undertaken for microscopic morphology. Pityrosporum versicolor cases were subjected to $\mathrm{KOH}$ mount and cultured on SDA with olive oil overlay (Jagadish chander, 2009) The culture studies and identification were done by standard methods.

\section{Identification of Non-Dermatophyte Molds (NDM)}

The NDM that are considered as pathogen for onychomycosis are Aspergillus, Scopulariopsis spp, Acremonium spp, Fusarium spp, Curvurlaria spp, Penicillium spp (Singal et al., 2011), Molds are considered pathogens when the following criteria are fulfilled:

1. Nail abnormalities consistent with diagnosis.
2. Positive direct microscopy visualizing hyphae in the nail keratin

3. Failure to isolate a dermatophyte in the culture

4. Growth of more than five colonies of the same mold in atleast two consecutive nail samplings.(Tosti A, et al., 2000)

\section{Results and Discussion}

A total of 150 clinically suspected cases were enrolled in the study comprising 98 $(65.3 \%)$ males and $52(34.7 \%)$ females with a male to female ratio of 1.8:1. None of them had any systemic disease Similar finding was observed by vyoma chudasama et al(2014) with a male to female ratio of 2.1:1.The male preponderance may be correlated with the occupational hazards related to their nature of work, the frequent interaction with different people of the society. Majority of cases screened belonged to age group between 11-60 yrs. The highest number i.e., $32(21.3 \%)$ patients belonged to 31-40 year age group. The probable reason for this age predilection is excessive sweating due to excessive physical activity, as a consequence, in addition the tropical climatic conditions. Similar findings were noted in studies of Amita pandey et al., 2013. The most common clinical presentation is tinea corporis ie.45 cases $(30 \%)$ followed by onychomycosis 38 $(25.3 \%)$, tinea capitis $17(11.3 \%)$, tinea cruris $16(10.6 \%)$, tinea pedis $12(8 \%)$, tinea corporis+cruris 7 cases $(4.6 \%)$, tinea faciei and tinea mannum 4 each $(2.6 \%)$ and pityriasis versicolor 7(4.6\%).

Out of 150 cases fungal elements were seen in 107 cases while culture was positive in 85 cases. Dermatophytes accounted for 49 
(57.6\%) of total culture positive cases followed by non dermatophyte moulds 18 $(21.3 \%)$, candida $15(17.6 \%)$ and malassezia spp 3 (3.5\%).Non dermatophytes were isolated from cases of onychomycosis, tinea pedis and tinea capitis.

Among the Non dermatophytes, filamentous moulds were the most common i.e 18 (50 $\%)$ of which $15(41.6 \%)$ were from cases of onychomycosis and $3(8.4 \%)$ from cases of T. capiitis. Similarly Kumaran et al., 2014 and Aruna vyas et al., 2013, reported non dermatophyte moulds from cases of Onychomycosis and T.capitis. The T.capitis cases in which Non dermatophyte moulds were isolated were chronic cases and seen in adults. In these cases NDM s were seen in direct microscopy and were isolated in pure cultures. The pattern of isolations of non dermatophyte moulds include Aspergillus sps 9(50\%), Fusarium Sps 2(11.1\%), Pencillium sps including marnefi,
Paeciliomyces, Scopulariopsis, Alternaria and Acremonium sps are 1(5.5\%) each. Aspergillus sps were the majority. Only I isolate i.e Alternaria belonged to pheoid group. Out of $15(17.6 \%)$ isolations of candida, $8(9.4 \%)$ are from cases of onychomycosis and $6(7 \%)$ from $\mathrm{T}$. mannum.

Candida were the second most common 15 (41.6\%), 9(25\%) are from cases of onychomycosis and $6(16.6 \%)$ from $T$. pedis. C.albicans was the most common species isolated and was isolated in cases of Onychomycosis and T.pedis. Non albicans isolations were 4 (29.5) and were from Onychomycosis and T.Pedis. Speciation in chrome agar was done. The non albicans isolated were C.parapsilosis and C.krusei. All 3(8.4\%) Malassezia spp were isolated from 7 cases presented as Pityriasis vesicolor.

Table.1 Pattern of Culture Isolates $(n=85)$

\begin{tabular}{|c|l|c|c|}
\hline Sno & \multicolumn{1}{|c|}{ Fungal isolate } & Number & \% \\
\hline $\mathbf{1}$ & Dermatophytes & 49 & 57.6 \\
\hline $\mathbf{2}$ & Candida & 15 & 17.6 \\
\hline $\mathbf{3}$ & Malassezia spp & 3 & 3.5 \\
\hline $\mathbf{4}$ & Non dermatophyte moulds & 18 & 21.3 \\
\hline
\end{tabular}

Non dermatophytes were isolated from cases of onychomycosis, tinea pedis and tinea capitis

Table.2 Clinical Presentations and Non Dermatophytes Isolated $(n=36)$

\begin{tabular}{|c|l|c|c|c|}
\hline S.No & \multicolumn{1}{|c|}{ Clinical presentation } & Candida & Malassezia & Moulds \\
\hline 1 & Onychomycosis & $9(25 \%)$ & - & $15(41.6 \%)$ \\
\hline 2 & Tinea capitis & - & - & $3(8.4 \%)$ \\
\hline 3 & Tinea pedis & $6(16.6 \%)$ & - & - \\
\hline 4 & Pityriasis versicolor & - & $3(8.4 \%)$ & - \\
\hline \multicolumn{2}{|c}{ Total } & $15(41.6 \%)$ & $3(8.4 \%)$ & $18(50 \%)$ \\
\hline
\end{tabular}


Table.3 Frequency of Non Dermatophyte Moulds Isolated $(n=18)$

\begin{tabular}{|c|c|c|c|}
\hline Sno & Fungal isolate & Number & $\%$ \\
\hline 1 & Aspergillus niger & 2 & 11.1 \\
\hline 2 & Aspergillus flavus & 4 & 22.2 \\
\hline 3 & Aspergillus fumigates & 3 & 16.6 \\
\hline 4 & Alternaria & 1 & 5.5 \\
\hline 5 & Acremonium & 1 & 5.5 \\
\hline 6 & Curvularia & 1 & 5.5 \\
\hline 7 & Fusarium & 2 & 11.1 \\
\hline 8 & Scopulariopsis & 1 & 5.5 \\
\hline 9 & Paeciliomyces & 1 & 5.5 \\
\hline 10 & Penicillum marneffi & 1 & 5.5 \\
\hline 11 & Penicillium & 1 & 5.5 \\
\hline
\end{tabular}

Table.4\% of Candida Albicans and Non Albicans sps Isolated in Different Clinical Presentations $(\mathrm{n}=15)$

\begin{tabular}{|l|l|l|l|l|l|}
\hline Sno & $\begin{array}{l}\text { Clinical } \\
\text { presentation }\end{array}$ & $\begin{array}{l}\text { Candida } \\
\text { albicans }\end{array}$ & $\%$ & Non albicans spp & $\%$ \\
\hline 1 & Onychomycosis & 6 & 40 & 2 & 13.3 \\
\hline 2 & T.pedis & 5 & 33.4 & 2 & 13.3 \\
\hline \multicolumn{2}{|l|}{ Total } & 11 & 73.4 & 4 & 26.6 \\
\hline
\end{tabular}


Int.J.Curr.Microbiol.App.Sci (2016) 5(4): 452-458

Figure.1 LPCB Mount of Scopulariopsis brevicaulis

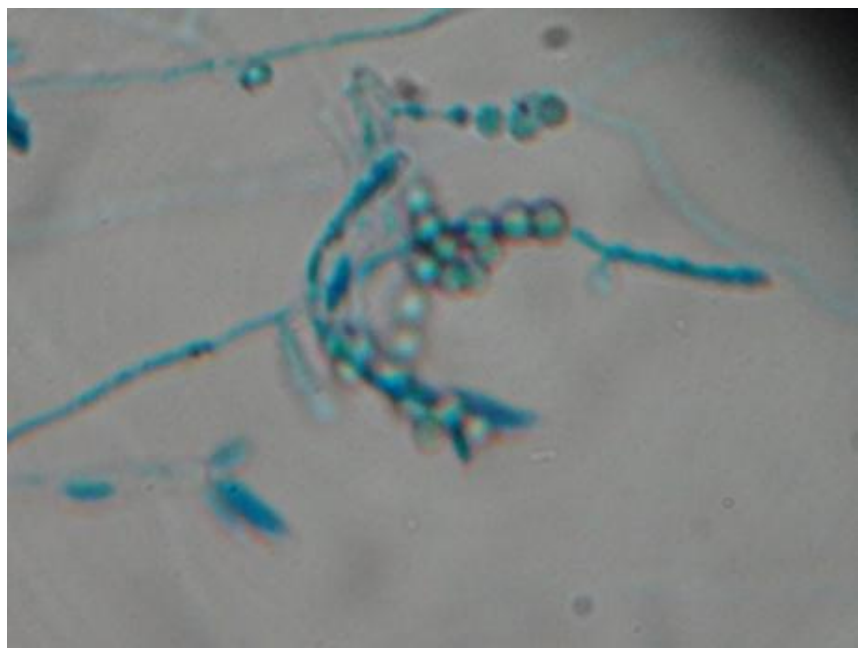

Figure.2 Finger Nail Onychomycosis

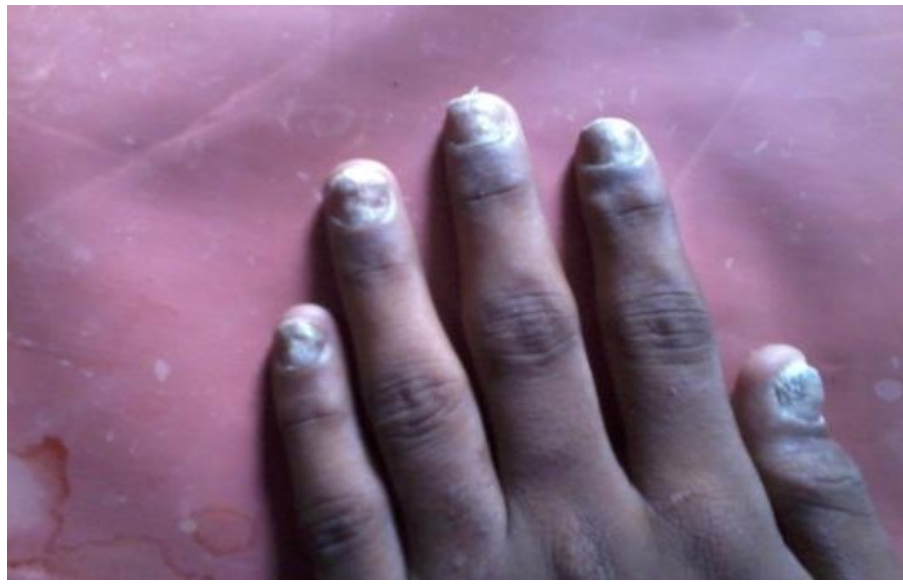

Figure.3 Chrome Agar Showing Candia Spp

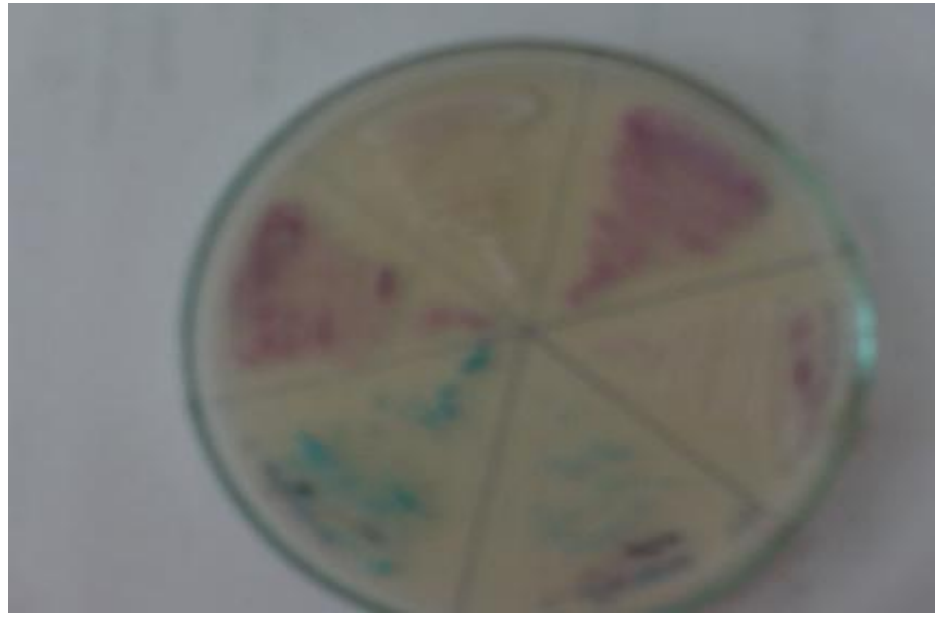


Most of our isolates were from clinical presentations of Onychomycosis and T.pedis, in which the etiological agents can be dermatophytes or Non dermatophytes. So laboratory assistance to know the etiological agent is a must, especially in treatment of chronic cases in these clinical presentations. Also few isolations were non albicans candida, which makes yeast speciation must. In interdigitalis variant of T.pedis candida spp were isolated. This was mostly seen in women who were constantly exposed to wet environment.

There was increased number of non dermatophytes isolated in the present study this might be due to the commonest age group affected in onychomycosis was 51-60 yrs. The conditions favouring the growth of NDM were old nails, farmers, bad foot care and hot, humid climate as well(Kaur et al $\left.{ }^{13}\right)$. Though they are normally considered as contaminants they are capable of invading the nail as primary pathogens. Some studies have reported NDM in cutaneous mycosis, in the present study isolations were only in T.Capitis and onychomycosis. Their role in cutaneous mycosis is still not completely evaluated. So larger studies are very much needed for better understanding.

\section{References}

Amita Pandey, Manish Pandey, Tomar, R.S. 2013. Isolation of opportunistic fungi from skin samples at Gwalior, Madhya Pradesh, India. Int. J. Curr. Sci., 7: E139-141.

Aruna Aggarwal, Usha Arora, Saroj Khanna. 2002. Clinical and Mycological study of Superficial mycosis in Amritsar. Indian J. Dermatol., 47(4): 218-220.

Aruna Vyas, Nazeen Pathan, Rajani Sharma, Leela Vyas. 2013. A Clinico Mycological Study of Cutaneous
Mycoses in Sawai Man Singh Hospital of Jaipur, North India. Ann. Med. Health Sci. Res., 3(4): 593597.

Dogra, S., Kumar, B., Bhansali, A., Chakrabarthy, A. 2002. Epidemiology of onychomycosis in patients with diabetes mellitus in India. Int. J. Dermatol., 41: 647-51.

EI Batawi, M.M., Arnaot, H., Shoeib, S., Bosseila, M., EI Fangary, M., Helmy, A.S. 2006. Prevalence of non-dermatophyte molds in patients with abnormal nails. Egyptian Dermatol. Online J., 2: 11.

Kumaran, G., Jeya, M. 2014. Clinico Mycological profile of dermatophytic infections, Int. J. Pharm. Bio. Sci., 5(2): (B)1-5.

Jagdish Chander. 2009. Textbook of Mycol., $3^{\text {rd }}$ Ed: Mehta publishers; p-122142, 266-283, 508-516.

Kaur, R., Kashyap, B., Bhalla, P. 2008. Onychomycosis-Epidemiology, Diagnosis and Management. Indian J. Med. Microbiol., 26(2): 108-116.

Naidu, J. 1993. Growing incidence of cutaneous and inguinal infections by non dermatophytic fungi at Jabalpur(MP). Ind. J. Pathol. Microbiol., 36: 113-8.

Singal, A., Khanna, D. 2011. Onychomycosis: Diagnosis and management. Indian J. Dermatol. Venereol. Leprol., 7(6): 659-72.

Topley, Wilson, S. 2005. Microbiol. Microbial Infections, Medical Mycol., $10^{\text {th }}$ edition, William G. Merz \& Roderick J. Hay; Edward Arnold (Publishers) Ltd, Volume 4.

Tosti, A., Piraccini, B.M., Lorenzi, S. 2000. Onychomycosis caused by non dermatophyte moulds: Clinical features and response to treatment in 59 cases. J. Am. Acad. Dermatol., 42: $217-24$. 
Vyoma Chudasama, Hasumati Solanki, in tertiary care hospital. Int. J. Sci. Minesh Vadsmiya,Tanuja Javadekar. Res., 3(3): 222-224. 2014. A study of superficial mycosis

\section{How to cite this article:}

Manjula, V., and Parameswari, K. 2016. A Study of Nondermatophytic Dermatomycosis in Patients Attending a Tertiary Care Hospital in Vijayawada, Andhra Pradesh, India. Int.J.Curr.Microbiol.App.Sci.5(4): 452-458. doi: http://dx.doi.org/10.20546/ijcmas.2016.504.053 